\title{
Neutrophil to lymphocyte ratio and platelet to lymphocyte ratio are associated with cryptogenic stroke in patients with patent foramen ovale
}

\author{
Fatma Nihan Turhan Caglar ${ }^{1}$, Murat Erdem Alp ${ }^{1}$, Dilay Karabulut ${ }^{1}$, Nilgun Isiksacan², Fahrettin Katkat ${ }^{3}$, \\ Hulya Cebe ${ }^{4}$, Ersan Oflar ${ }^{1}$, Didem Melis Oztas ${ }^{5}$, Orhan Rodoplu6, Orcun Unal7 , Cenk Conkbayir ${ }^{8}$, \\ Faruk Akturk ${ }^{1}$, Murat Ugurlucan ${ }^{9}$
}

\author{
${ }^{1}$ Cardiology Department, Bakirkoy Dr Sadi Konuk Training and Research Hospital, \\ Istanbul, Turkey \\ 2Biochemistry Department, Bakirkoy Dr Sadi Konuk Training and Research Hospital, \\ Istanbul, Turkey \\ ${ }^{3}$ Cardiology Department, Bagcilar Training and Research Hospital, Istanbul, Turkey \\ ${ }^{4}$ Cardiology Department, Ercis State Hospital, Van, Turkey \\ ${ }^{5}$ Cardiovascular Surgery Clinic, Bagcilar Training and Research Hospital, Istanbul, \\ Turkey \\ ${ }^{6}$ Cardiovascular Surgery Clinic, Kadikoy Medicana Hospital, Istanbul, Turkey \\ ${ }^{7}$ Cardiovascular Surgery Clinic, Yedikule Chest Diseases and Thoracic Surgery \\ Education and Research Hospital, Istanbul, Turkey \\ ${ }^{8}$ Department of Cardiology, Near East University, Nicosia, Cyprus \\ ${ }^{9}$ Department of Cardiovascular Surgery, Medical Faculty, Istanbul Medipol University, \\ Istanbul, Turkey
}

Submitted: 19 November 2019

Accepted: 27 April 2020

Arch Med Sci Atheroscler Dis 2020; 5: e112-e117

DOI: https://doi.org/10.5114/amsad.2020.95946

Copyright (c) 2020 Termedia \& Banach

\section{Abstract}

Introduction: Although most ischaemic strokes are due to cardioembolism, about $25-40 \%$ of strokes are cryptogenic. Patent foramen ovale has been associated with cryptogenic stroke; however, the precise mechanism of this association has not been demonstrated. The aim of this study was to evaluate the association between inflammatory markers and cryptogenic stroke in patients with patent foramen ovale.

Material and methods: We included 206 patients with patent foramen ovale. Ninety-four (45.63\%) out of 206 patients had had stroke, and 112 (54.37\%) had not had stroke. The ratio of the total neutrophil count to the total lymphocyte count was defined as the neutrophil to lymphocyte ratio, and the ratio of the absolute platelet count to the absolute lymphocyte count was determined as the platelet to lymphocyte count.

Results: The neutrophil to lymphocyte ratio was significantly higher in patients who had stroke than in those who did not $(2.41 \pm 1.69$ vs. $2.19 \pm 1.74$, $p=0.047$ ). Although the platelet to lymphocyte count was also higher in patients who had had stroke than in those who had not, it was not statistically significant $(120.94 \pm 55.45$ vs. $118.01 \pm 52.21, p=0.729) .1 .62$ was the cut-off value for neutrophil to lymphocyte ratio to be associated with stroke with $73.4 \%$ sensitivity and $45.05 \%$ specificity $(p=0.042)$.

Conclusions: This study demonstrated that elevated neutrophil to lymphocyte ratio and platelet to lymphocyte count could be associated with cryptogenic stroke in patients with patent foramen ovale.

Key words: neutrophil/lymphocyte ratio, platelet/lymphocyte ratio, stroke, patent foramen ovale.

\author{
Corresponding author: \\ Fatma Nihan \\ Turhan Caglar \\ Cardiology Department \\ Bakirkoy Dr Sadi Konuk \\ Training and Research \\ Hospital \\ Istanbul, Turkey \\ E-mail: nhnturhan@gmail. \\ com
}




\section{Introduction}

Stroke is one of the most important causes of mortality and morbidity worldwide [1]. The percentage of ischaemic stroke is the highest among all stroke types, which is more than $80 \%$ [2]. Although most ischaemic strokes are due to cardioembolism, about $25-40 \%$ of strokes are cryptogenic [3, 4]. Patent foramen ovale (PFO) has been associated with cryptogenic stroke; however, the precise mechanism of this association has not been demonstrated $[5,6]$. The prevalence of PFO was shown to be higher in patients with cryptogenic stroke than in the general population [6]. Moreover, some randomised, controlled trials demonstrated a decreased stroke recurrence risk after PFO closure, although such an association has not been confirmed with meta-analysis [5-7].

It has been postulated that inflammation plays a crucial role in all stages of stroke [8]. Chemokines and cytokines released from ischaemic brain tissue attract leukocytes from peripheral blood [8]. Neutrophils are the main leucocytes that aggravate brain injury during ischaemia [9]. It has been found that higher neutrophil levels are associated with larger infarct sizes and more severe strokes [10]. On the other hand, lymphocytes, which are also a part of the inflammatory response, which supress and control the exacerbated inflammatory process, are decreased in peripheral blood of patients with stroke [11]. Hence, the neutrophil to lymphocyte ratio (NLR) is suggested as an inflammation marker of stroke [12]. Similarly, platelet activation contributes to the inflammation, and consequently relative thrombocytosis and initiation and progression of atherosclerosis [12, 13]. Recent studies have demonstrated higher platelet to lymphocyte (PLR) values in patients with stroke [14].

High NLR, PLR, and PFO are known to be independent contributing factors for stroke development, but their additive role in cryptogenic stroke has not been fully investigated. The aim of this study was to evaluate whether NLR and PLR predispose to cryptogenic stroke in patients with PFO.

\section{Material and methods}

\section{Study population}

We included 206 consecutive patients with PFO in this prospective study. The presence of PFO was demonstrated by transoesophageal echocardiogram (TEE) in all subjects. Ninety-four of these patients were referred to the TEE laboratory from various neurology clinics with the diagnosis of acute ischaemic cryptogenic stroke. Stroke was defined as sudden onset of global or cerebral dysfunction persisting for more than $24 \mathrm{~h}$. All the patients underwent workup for the determination of the source of the embolism leading to stroke, and the ascending aorta, aortic arch, carotid, and vertebral arteries were thoroughly investigated.

A total of 112 healthy controls were referred to the TEE laboratory with suspicion of PFO. Subjects with coronary artery disease, carotid and/or aortic atherosclerotic disease, congestive heart failure, valvular heart disease, paroxysmal atrial fibrillation or any kind of arrythmia, malignancy, chronic obstructive lung disease, complicated diabetes, renal failure, liver failure, major rheumatic diseases, active inflammatory diseases, non-cryptogenic stroke, haemorrhagic stroke, surgery, or trauma within the preceding three months and those with missing laboratory data were excluded. Additionally, patients with signs and symptoms of any kind of recent infection were also excluded because leucocytes, neutrophils, and lymphocytes are elevated during the course of an infection.

\section{Ethics}

This study was conducted in accordance with the Declaration of Helsinki ethical principles for medical research involving human subjects. Study protocol was explained in detail to the patients and their relatives, and a written, informed consent form was obtained from all study participants. The study was approved by the Intuitional Ethics Committee (No. 2017-17-28).

\section{Blood analysis}

Complete blood cell counts, including total white blood cells (WBC), neutrophils, lymphocytes, and platelets, were obtained at the time of admission to the TEE laboratory in all subjects. The time window for blood sampling was more than $48 \mathrm{~h}$ to less than one week in patients with stroke. The NLR and the PLR were calculated as neutrophil count divided by lymphocyte count, and platelet count divided by lymphocyte count, respectively.

\section{Assessment of TEE}

All patients underwent complete two-dimensional TEE with an echocardiography device (EpIQ 7C, Philips Healthcare) operated by a single experienced cardiologist. Data acquisition was performed with a $7 \mathrm{MHz}$ transducer. Mid-oesophageal long-axis view was used for PFO recognition. TEE parameters were recorded according to the recent related guidelines of the American Society of Echocardiography [15].

\section{Statistical analysis}

MedCalc Statistical Software version 12.7.7 (MedCalc Software bvba, Ostend, Belgium; http:// www.medcalc.org; 2013) computer software was used for statistical analysis. Normal distribution of continuous variables was analysed by Shapiro-Wilk 
Fatma Nihan Turhan Caglar, Murat Erdem Alp, Dilay Karabulut, Nilgun Isiksacan, Fahrettin Katkat, Hulya Cebe, Ersan Oflar, Didem Melis Oztas, Orhan Rodoplu, Orcun Unal, Cenk Conkbayir, Faruk Akturk, Murat Ugurlucan

test. Normally distributed numeric variables were compared using Student's $t$-test, and non-normally distributed variables were analysed using the Kruskal-Wallis test. Spearman's rank test was employed to analyse correlations among numeric variables. Binary logistic regression test was employed to analyse correlations among categorical variables, and odds ratio and $95 \%$ confidence intervals were calculated. The NLR and PLR were evaluated by comparing the areas under the receiver operating characteristic curve (AUC) in predicting the patients with PFO and stroke. The linear correlations were evaluated to determine the relationship between lymphocyte counts, NLR, PLR, and stroke. Statistical significance was accepted as $p<0.05$.

\section{Results}

The demographic features and laboratory findings of the patients are presented in Table I. Lab- oratory findings are presented in Table II. Accordingly, haemogram and haemotocrit values were higher in patients with stroke than in healthy individuals (13.98 \pm 1.57 vs. $13.51 \pm 1.6, p=0.012$ and $42.17 \pm 4.2$ vs. $41.04 \pm 4.1, p=0.017$, respectively). Neutrophil count was also higher in the stroke group than in the healthy group (5.24 \pm 2.56 vs. $4.46 \pm 1.87, p=0.004)$. PLR was not significantly different between the groups (120.94 \pm 55.45 vs. $118.01 \pm 52.21, p=0.72)$. NLR was significantly higher in the stroke group than in the control group $(2.41 \pm 1.69$ vs. $2.19 \pm 1.74, p=0.047)$. ROC analysis for NLR and PLR is presented in Table III. Accordingly, 1.62 was the cut-off value for NLR to be associated with stroke, with $73.4 \%$ sensitivity and $45.05 \%$ specificity $(p=0.042$ ) (Figure 1 ). 96.21 was the cut-off value for PLR, with $70.21 \%$ sensitivity and $39.29 \%$ specificity $(p=0.729)$ (Figure 2). Correlation analysis revealed that NLR was

Table I. Demographic features of the patients in groups

\begin{tabular}{|lccl|}
\hline Parameter & $\begin{array}{c}\text { Control group } \\
n(\%)\end{array}$ & $\begin{array}{c}\text { Stroke group } \\
n(\%)\end{array}$ & $P$-value \\
\hline Gender & $65(58.04)$ & $33(35.11)$ & 0.001 \\
\hline Hypertension & $63(56.25)$ & $43(45.74)$ & 0.162 \\
\hline Diabetes mellitus & $52(46.43)$ & $49(52.13)$ & 0.484 \\
\hline Hyperlipidaemia & $54(48.21)$ & $42(44.68)$ & 0.675 \\
\hline Family history & $49(43.75)$ & $45(47.87)$ & 0.577 \\
\hline Smoking & $67(59.82)$ & $54(57.45)$ & 0.777 \\
\hline
\end{tabular}

Table II. Laboratory findings and ages of the patients in the groups

\begin{tabular}{|c|c|c|c|}
\hline Parameter & $\begin{array}{c}\text { Control group } \\
\text { Mean } \pm \text { SD } \\
\text { Med. (min.-max.) }\end{array}$ & $\begin{array}{c}\text { Stroke group } \\
\text { Mean } \pm \text { SD } \\
\text { Med. (min.-max.) }\end{array}$ & $P$-value \\
\hline Haemogram & $\begin{array}{c}13.51 \pm 1.6 \\
13.3(10-17.9)\end{array}$ & $\begin{array}{c}13.98 \pm 1.57 \\
14.1(9.65-17.3)\end{array}$ & 0.012 \\
\hline Haematocrit & $\begin{array}{c}41.04 \pm 4.1 \\
40.56(29.4-50.6)\end{array}$ & $\begin{array}{c}42.17 \pm 4.2 \\
42.8(30.8-51.7)\end{array}$ & 0.017 \\
\hline Lymphocyte & $\begin{array}{c}2.39 \pm 0.83 \\
2.25(0.65-5.39)\end{array}$ & $\begin{array}{c}2.41 \pm 0.63 \\
2.36(0.65-3.84)\end{array}$ & 0.364 \\
\hline Leucocyte & $\begin{array}{c}7.65 \pm 2.12 \\
7.53(3.94-14.7)\end{array}$ & $\begin{array}{c}8.56 \pm 2.68 \\
7.9(4.47-22.19)\end{array}$ & 0.005 \\
\hline Platelet & $\begin{array}{l}255.46 \pm 67.33 \\
246.5(91-522)\end{array}$ & $\begin{array}{c}268.7 \pm 64 \\
260(117-486)\end{array}$ & 0.098 \\
\hline Platelet/lymphocyte & $\begin{array}{c}118.01 \pm 52.21 \\
108.49(41.17-411.82)\end{array}$ & $\begin{array}{c}120.94 \pm 55.45 \\
111.62(56.4-466.15)\end{array}$ & 0.729 \\
\hline Leucocyte/lymphocyte & $\begin{array}{c}3.55 \pm 1.85 \\
3.08(1.72-16.53)\end{array}$ & $\begin{array}{c}3.83 \pm 2.05 \\
3.25(2.14-14.2)\end{array}$ & 0.065 \\
\hline Neutrophil & $\begin{array}{c}4.46 \pm 1.87 \\
4(1.48-12.09)\end{array}$ & $\begin{array}{c}5.24 \pm 2.56 \\
4.67(1.88-19.14)\end{array}$ & 0.004 \\
\hline Neutrophil/lymphocyte & $\begin{array}{c}2.19 \pm 1.74 \\
1.72(0.5-14.73)\end{array}$ & $\begin{array}{c}2.41 \pm 1.69 \\
1.91(0.9-11.84)\end{array}$ & 0.042 \\
\hline Age & $\begin{array}{c}39.98 \pm 15.81 \\
37(17-79)\end{array}$ & $\begin{array}{c}51.19 \pm 11.81 \\
51(17-79)\end{array}$ & $<0.001$ \\
\hline
\end{tabular}


Table III. Receiver operating characteristics (ROC) curve analysis of neutrophil/lymphocyte and platelet/lymphocyte ratios

\begin{tabular}{|lccccccccc|}
\hline $\begin{array}{l}\text { Stroke group vs. } \\
\text { control group }\end{array}$ & AUC & P-value & Cut-off & $\begin{array}{c}\text { Sensi- } \\
\text { tivity }\end{array}$ & $\begin{array}{c}95 \% \\
\text { Lower } \\
\mathrm{Cl}\end{array}$ & $\begin{array}{c}95 \% \\
\text { Upper } \\
\mathrm{Cl}\end{array}$ & $\begin{array}{c}\text { Specific- } \\
\text { ity }\end{array}$ & $\begin{array}{c}95 \% \\
\text { Lower } \\
\mathrm{Cl}\end{array}$ & $\begin{array}{c}95 \% \\
\text { Upper } \\
\mathrm{Cl}\end{array}$ \\
\hline NLR & 0.581 & 0.042 & 1.62 & 73.40 & 63.3 & 82.0 & 45.05 & 35.6 & 54.8 \\
\hline PLR & 0.514 & 0.729 & 96.21 & 70.21 & 59.9 & 79.2 & 39.29 & 30.2 & 49.0 \\
\hline
\end{tabular}

NLR - neutrophil/lymphocyte, PLR - platelet/lymphocyte.

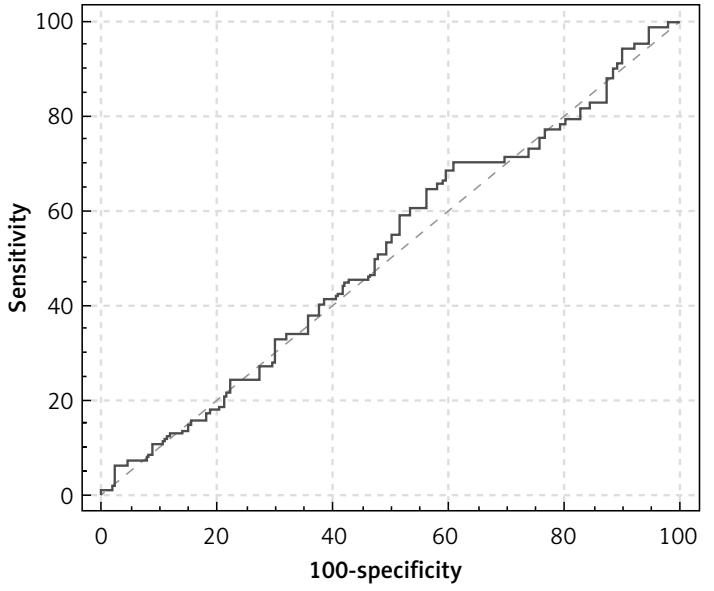

Figure 1. Receiver operating characteristics (ROC) curve analysis revealed that the $P L R \geq 96.21$ was predictive of stroke in patients with PFO with sensitivity $70.21 \%$, specificity $39.39 \%, p=0.729$

positively correlated with leucocyte count ( $p<$ 0.001) (Table IV). There was a negative correlation between PLR and haemogram and haematocrit levels, and a positive correlation between PLR and neutrophil $(p=0.006, p=0.011$, and $p<0.001$, respectively) (Table IV).

\section{Discussion}

Our study demonstrated that the NLR of stroke patients with PFO was higher than those without stroke. Also, PLR was elevated in the patient group compared to controls, but this was not statistically significant. To the best of our knowledge, this is the first study that has evaluated the association between these inflammatory markers and stroke risk in patients with PFO. Moreover, 1.62 was determined to be the cut-off value for NLR to predict stroke in patients with PFO; however, the sensitivity and especially the specificity of this cut-off value were low $(73.4 \%$ sensitivity and $45.05 \%$ specificity).

The literature includes studies regarding the development of stroke in various disease settings such as prostate [16] and breast cancer [17]. However, as a cardiac disorder, estimation of development of ischaemic stroke is especially clinically important for patients with PFO, where PFO closure, although still controversial, is an option

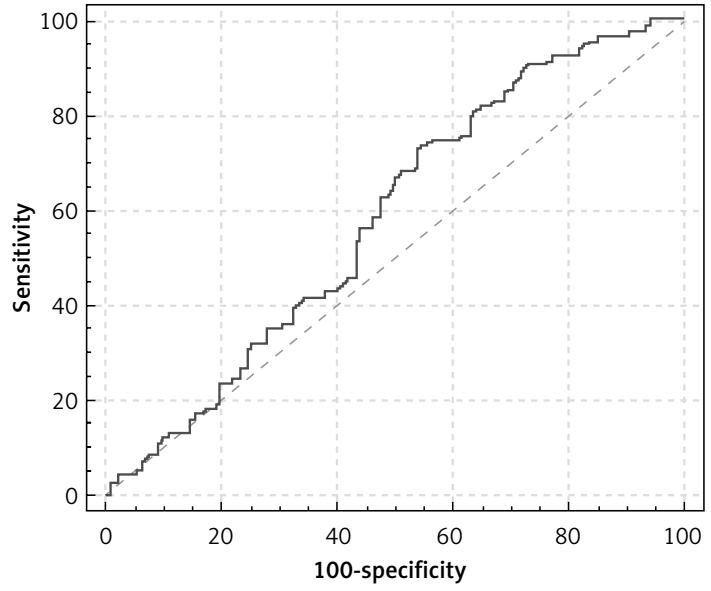

Figure 2. Receiver operating characteristics (ROC) curve analysis revealed that the NLR $\geq 1.62$ was predictive of stroke in patients with PFO with sensitivity $73.4 \%$, specificity $45.5 \%, p=0.042$

Table IV. Correlation analysis of neutrophil/lymphocyte and platelet/lymphocyte ratio

\begin{tabular}{|c|c|c|c|}
\hline Parameter & & NLR & PLR \\
\hline \multirow[t]{2}{*}{ Haemogram } & $r$ & -0.075 & -0.190 \\
\hline & $p$ & 0.288 & 0.006 \\
\hline \multirow[t]{2}{*}{ Haematocrit } & $r$ & -0.112 & -0.178 \\
\hline & $p$ & 0.109 & 0.011 \\
\hline \multirow[t]{2}{*}{ Lymphocyte } & $r$ & -0.610 & -0.683 \\
\hline & $p$ & $<0.001$ & $<0.001$ \\
\hline \multirow[t]{2}{*}{ Leucocyte } & $r$ & 0.368 & -0.120 \\
\hline & $p$ & $<0.001$ & 0.085 \\
\hline \multirow[t]{2}{*}{ Platelet } & $r$ & -0.038 & 0.452 \\
\hline & $p$ & 0.585 & $<0.001$ \\
\hline \multirow{2}{*}{$\begin{array}{l}\text { Leucocyte/ } \\
\text { lymphocyte }\end{array}$} & $r$ & 0.972 & 0.580 \\
\hline & $p$ & $<0.001$ & $<0.001$ \\
\hline \multirow[t]{2}{*}{ Neutrophil } & $r$ & 0.733 & 0.143 \\
\hline & $p$ & $<0.001$ & 0.041 \\
\hline \multirow[t]{2}{*}{ Age } & $r$ & 0.106 & 0.021 \\
\hline & $p$ & 0.130 & 0.761 \\
\hline
\end{tabular}

NLR - neutrophil/lymphocyte, PLR - platelet/lymphocyte. 
that may preclude worse outcome $[5,18]$. Local intraseptal thrombosis and paradoxical embolism are proposed as the main mechanisms of stroke in patients with PFO [6]. However, the existence of PFO seems not to be the exclusive reason for stroke [5]. Other parameters such as the morphology of PFO, presence of septal aneurysm, and deep venous thrombosis are sought before PFO closure to reduce recurrent stroke risk $[5,6]$. Inflammation is related with an increased risk of thrombosis [13, 19]. To date, the association between NLR and $P L R$, which are markers of inflammation, atherosclerosis, and stroke, have not been evaluated in patients with PFO. Our study is the first to demonstrate such a relationship.

Recent research has revealed that haematological markers such as NLR and PLR are more powerful inflammatory biomarkers than total WBC count in many diseases including stroke, atrial fibrillation, and myocardial infarction [20, 21]. The neutrophil/lymphocyte ratio (NLR) has been shown to predict cardiovascular events in several studies [22]. Shah et al. demonstrated that elevated NLR in healthy subjects is a risk factor for increased prospective cardiovascular mortality [23]. Suh et al. indicated increased prospective ischaemic stroke risk among asymptomatic patients who had elevated NLR [22]. Also, other relevant studies suggested the addition of NLR to traditional stroke and cardiovascular disease risk prediction models [22]. Moreover, the prognostic significance of these markers has also been demonstrated in various diseases such as stroke, heart failure, and peripheral arterial occlusive disease [12, 24, 25]. For instance, Fang et al. showed that the NLR significantly and independently predicted in-hospital mortality in patients who had ischaemic stroke [24]. Similarly, Tokgoz et al. and Celikbilek et al. also found similar correlation between clinical outcome and NLR in patients hospitalised with stroke [26, 27]. Additionally, high NLR has been assessed in venous thrombosis [28]. The investigators of the Tromso study indicated a correlation between elevated NLR and mortality risk among patients with venous thromboembolism [28].

Similarly to NLR, PLR is an easy-to-obtain, inexpensive blood test reflecting platelet reactivity [14]. Previous studies have demonstrated that PLR and NLR are feasible markers associated with thrombotic disorders [29, 30]. Ming et al. demonstrated increased NLR and PLR among patients with unprovoked acute deep vein thrombosis and highlighted the potential diagnostic value of these markers in venous thrombosis [31]. Furthermore, Ozcan Cetin et al. showed the prognostic potential of PLR in their study, which indicated an association between high PLR and in-hospital mortality and long-term adverse events in the setting of acute pulmonary embolism [32]. Artoni et al. found increased risk of provoked cerebral vein thrombosis in patients with high PLR values [33]. The importance of PLR in atherosclerosis has also been investigated [34]. Maimaiti et al. demonstrated elevated PLR as a marker for both predicting insufficient coronary reperfusion after myocardial infarction and for development of in-hospital adverse events [34]. Altintas et al. claimed that an increase in PLR values was associated with aggravating inflammatory process, which led to silent brain infarcts in patients with paroxysmal atrial fibrillation [35].

The single-centred design and small sample size are the major limitations that might have reduced the power of the study. The sensitivity and specificity of NLR and PLR were low in predicting stroke due to the increased range of NLR and PLR levels and the small sample size. Also, this was an observational and nonrandomised study; hence, further randomised studies to evaluate the role of NLR and PLR on PFO and stroke are warranted. As a last limitation, we only measured the haematological markers once, but a serial measurement of the parameters during follow-up might increase the power of the predictions of the studies.

In conclusion, while NLR was significantly higher, PLR was not significantly higher in patients with PFO who had stroke when compared with healthy individuals. The results of our study suggest that these markers may be associated with risk of ischaemic stroke in patients with PFO. Further large-scale studies are warranted to evaluate the incremental value of NLR and PLR in order to predict the development of ischaemic stroke in patients with PFO.

\section{Conflict of interest}

The authors declare no conflict of interest.

\section{References}

1. Meschia JF, Bushnell C, Boden-Albala B, et al.; American Heart Association Stroke Council; Council on Cardiovascular and Stroke Nursing; Council on Clinical Cardiology; Council on Functional Genomics and Translational Biology; Council on Hypertension. Guidelines for the primary prevention of stroke: a statement for healthcare professionals from the American Heart Association/American Stroke Association. Stroke 2014; 45: 3754-832.

2. Allen CL, Bayraktutan U. Oxidative stres and its role in the pathogenesis of ischmeic stroke. Int I Stroke 2009; 4: 461-70.

3. Petty GW, Brown RD Jr, Whisnant JP, Sicks JD, O'FalIon WM, Wiebers DO. Ischemic stroke subtypes: a population-based study of incidence and risk factors. Stroke 1999; 30: 2513-6.

4. Kotlęga D, Gołąb-Janowska M, Meller A, et al. Beneficial effects of pre-stroke statins use in cardioembolic stroke patients with atrial fibrillation: a hospital-based retrospective analysis. Arch Med Sci 2019; 15: 385-92. 
5. Köhrmann M, Schellinger PD, Tsivgoulis G, Steiner T. Patent foramen ovale: story closed ? J Stroke 2019; 21: 23-30.

6. Braemswig TB, Usnich T, Scheitz JF, et al. Early recurrent ischemic lesions in patients with cryptogenic stroke and patent foramen ovale:An observational study. Front Neurol 2018; 9: 996.

7. Søndergaard L, Kasner SE, Rhodes JF, et al. Patent foramen ovale closure or antiplatelet therapy for cryptogenic stroke. N Engl J Med 2017; 377: 1033-42.

8. Kim JY, Park J, Chang JY, Kim SH, Lee JE. Inflammation after ischemic stroke: the role of leukocytes and glial cells. Exp Neurobiol 2016; 25: 241-51.

9. Herz J, Sabellek P, Lane TE, Gunzer M, Hermann DM, Doeppner TR. Role of neutrophils in exacerbation of brain injury after focal cerebral ischemia in hyperlipidemic mice. Stroke 2015; 46: 2916-25.

10. Buck BH, Liebeskind DS, Saver JL, et al. Early neutrophilia is associated with volume of ischemic tissue in acute stroke. Stroke 2008; 39: 355-60.

11. Kim J, Song TJ, Park JH, et al. Different prognostic value of white blood cell subtypes in patients with acute cerebral infarction. Atherosclerosis 2012; 222: 464-7.

12. Uzun F, Erturk M, Cakmak HA, et al. Usefulness of the platelet-to-lymphocyte ratio in predicting long-term cardiovascular mortality in patients with peripheral arterial occlusive disease. Adv Interv Cardiol 2017; 13: 32-8.

13. Demir B, Caglar IM, Ungan I, Ugurlucan M, Tureli HO, Karakaya O. Mean platelet volume is elevated in patients with patent foramen ovale. Arch Med Sci 2013; 9: 1055-61.

14. Zhang Y, Yang P, Wang J. Peripheral blood platelet to lymphocyte ratio as potential diagnostic and prognostic markers of acute cerebral infarction and its clinical significance. Clin Lab 2019; 65. doi: 10.7754/Clin. Lab.2018.180912.

15. Silvestry FE, Cohen MS, Armsby LB, et al. Guidelines for the echocardiographic assessment of atrial septal defect and patent foramen ovale: from the American Society of Echocardiography and Society for cardiac angiography and interventions. J Am Soc Echocardiogr 2015; 28: 910-58.

16. Rethemiotaki I, Rethemiotakis A. Link between prostate cancer diagnosis and stroke in the United States during 2007-2017. Arch Med Sci Atheroscler Dis 2019; 4: e94-102.

17. Rethemiotaki I, Rethemiotakis A. Stroke and breast cancer in the United States during 2007-2017. Arch Med Sci Atheroscler Dis 2019; 4: e134-40.

18. Conkbayir C, Yigit Z, Hural R, et al. Do restoring and maintaining sinus rhythm have a beneficial effect on secondary prevention of stroke in patients with atrial fibrillation? A pilot study. Angiology 2019; 70: 916-20.

19. Gary T, Pichler M, Belaj K, et al. Platelet-to-lymphocyte ratio: a novel marker for critical limb ischemia in peripheral arterial occlusive disease patients. PLoS One 2013; 8: e67688.

20. Walsh SR, Cook EJ, Goulder F, Justin TA, Keeling NJ. Neutrophil-lymphocyte ratio as a prognostic factor in colorectal cancer. J Surg Oncol 2005; 91: 181e4.

21. Zahorec R. Ratio of neutrophil to lymphocyte countserapid and simple parameter of systemic inflammation and stress in critically ill. Bratisl Lek Listy 2001; 102: 5-14.

22. Suh B, Shin DW, Kwon HM, et al. Elevated neutrophil to lymphocyte ratio and ischemic stroke risk in generally healthy adults. PLoS One 2017; 12: e0183706.

23. Shah N, Parikh V, Patel N, et al. Neutrophil lymphocyte ratio significantly improves the Framingham risk score in prediction of coronary heart disease mortality: insights from the National Health and Nutrition Examination Survey-III. Int J Cardiol 2014; 171: 390-7.

24. Fang YN, Tong MS, Sung PH, et al. Higher neutrophil counts and neutrophil-to-lymphocyte ratio predict prognostic outcomes in patients after non-atrial fibrillation-caused ischemic stroke. Biomed J 2017; 40: 154-62.

25. Durmuş E, Kivrak T, Gerin F, Sunbul M, Sari I, Erdogan O. Neutrophil-to-lymphocyte ratio and platelet-to-lymphocyte ratio and predictors of heart failure. Arq Bras Cardiol 2015; 105: 606-13.

26. Tokgoz S, Keskin S, Kayrak M, Seyithanoglu A, Ogmegul A. Is neutrophil/lymphocyte ratio predict to shortterm mortality in acute cerebral infarct independently from infarct volume? J Stroke Cerebrovasc Dis 2014; 23: 2163-8.

27. Celikbilek A, Ismailogullari S, Zararsiz G. Neutrophil to lymphocyte ratio predicts poor prognosis in ischemic cerebrovascular disease. J Clin Lab Anal 2014; 28: 27-31.

28. Grimnes G, Horvei LD, Tichelaar V, Braekkan SK, Hansen JB. Neutrophil to lymphocyte ratio and future risk of venous thromboembolism and mortality: the Tromso Study. Haematologica 2016; 101: e401-4.

29. Vakili H, Shirazi M, Charkhkar M, Khaheshi I, Memaryan $M$, Naderian $M$. Correlation of platelet-to-lymphocyte ratio and neutrophil-to-lymphocyte ratio with thrombolysis in myocardial infarction frame count in ST-segment elevation myocardial infarction. Eur J Clin Invest 2017; 47: 322-7.

30. Kurtipek E, Buyukterzi Z, Buyukterzi M, Alpaydin MS, Erdem SS. Endothelial dysfunction in patients with pulmonary thromboembolism: neutrophil to lymphocyte ratio and platelet to lymphocyte ratio. Clin Respir J 2017; 11: 78-82.

31. Ming L, Zhiyun Jiang Z, Ma J, Wang $Q$, Wu F, Ping J. Platelet-to-lymphocyte ratio, neutrophil-to-lymphocyte ratio, and platelet indices in patients with acute deep vein thrombosis. Vasa 2018; 47: 143-7.

32. Ozcan Cetin EH, Cetin MS, Canpolat U, et al. Platelet-to-lymphocyte ratio as a novel marker of inhospital and long-term adverse outcomes among patients with acute pulmonary embolism: a single center large-scale study. Thromb Res 2017; 150: 33-40.

33. Artoni A, Abbattista M, Bucciarelli P, et al. Platelet to lymphocyte ratio and neutrophil to lymphocyte ratio as risk factors for venous thrombosis. Clin Appl Thromb Hemost 2018; 24: 808-14.

34. Maimaiti A, Li Y, Wang YT, et al. Association of platelet-to-lymphocyte count ratio with myocardial reperfusion and major adverse events in patients with acute myocardial infarction: a two-centre retrospective cohort study. BMJ Open 2019; 9: e025628.

35. Altintas O, Tasal A, Niftaliyev E, Kucukdagli O, Asil T. Association of platelet-to-lymphocyte ratio with silent brain infarcts in patients with paroxysmal atrial fibrillation. Neurol Res 2016; 38: 753-8. 